\title{
COMPARISON OF THE EFFECTS OF WALKING AND BENCH-STEP EXERCISE ON OSTEOCALCIN AND CTX-1 IN POST-MENOPAUSAL WOMEN WITH OSTEOPENIA
}

\author{
Ignatio Rika Haryono \\ Department of Physiology, Faculty of Medicine \\ Atma Jaya Catholic University of Indonesia, Jakarta 10440, Indonesia \\ Angela Tulaar \\ Department of Physic and Rehabilitation, Faculty of Medicine \\ Universitas Indonesia - Dr Cipto Mangunkusumo General Hospital \\ Jakarta 10430, Indonesia \\ Herawati Sudoyo \\ Eijkman Institute for Molecular Biology, Jakarta 10430, Indonesia \\ Ambrosius Purba \\ Department of Physiology, Faculty of Medicine \\ Padjadjaran University, Bandung 40161, Indonesia \\ Murdani Abdullah \\ Department of Internal Medicine, Division of Gastroenterology \\ Faculty of Medicine \\ Universitas Indonesia - Dr Cipto Mangunkusumo General Hospital \\ Jakarta 10430, Indonesia \\ Sri Widia Jusman \\ Department of Biochemistry and Molecular Biology, Faculty of Medicine \\ Universitas Indonesia, Jakarta 10430, Indonesia
}

\footnotetext{
Correspondence to: Ermita I. Ibrahim Ilyas, Faculty of Medicine, Department of Medical Physiology, Universitas Indonesia, Salemba Street No. 6, Central Jakarta 10430, Indonesia.

This is an Open Access article published by World Scientific Publishing Company. It is distributed under the terms of the Creative Commons Attribution 4.0 (CC-BY) License. Further distribution of this work is permitted, provided the original work is properly cited.
} 


\author{
Andri M. T. Lubis \\ Department of Orthopaedic and Traumatology, Faculty of Medicine \\ Universitas Indonesia - Dr Cipto Mangunkusumo General Hospital \\ Jakarta 10430, Indonesia \\ Ermita I. Ibrahim Ilyas \\ Department of Medical Physiology, Faculty of Medicine \\ Universitas Indonesia, Jakarta 10430, Indonesia \\ ermitailyas@gmail.com
}

Received 5 February 2017

Accepted 22 June 2017

Published 10 August 2017

\begin{abstract}
Purpose: Bench-step exercise produces biomechanical movements beneficial to improve bone remodeling. However, no studies have confirmed the effects of bench-step exercise (BE) on bone formation and resorption. The goal of this study is to compare the effects of bench-step and walking exercise (WE) on changes in osteocalcin and CTX-1 levels. Methods: Fifty-nine sedentary post-menopausal women with osteopenia (T-score between -1 and -2.5$)$ were randomly divided into two groups: WE group $(n=29)$ and BE group $(n=30)$. Subjects performed 12 weeks of exercise. The osteocalcin and CTX-1 levels were analyzed using enzyme-linked immunosorbent assay. Independent $t$-test or Wilcoxon test was used to analyze the osteocalcin and CTX-1 levels. The difference in changes in the osteocalcin and CTX-1 between the groups before and after was analyzed using Mann-Whitney test. Results: The results showed a significant increase in the osteocalcin and CTX-1 levels in both groups $(P<0.05)$. The increased levels of osteocalcin between groups were not statistically different $(P>0.367)$. The increase in CTX-1 resulting from BE was lower than that from WE $(P<0.048)$. Conclusion: This study indicates that BE may inhibit resorption stronger than WE.
\end{abstract}

Keywords: Bone formation; Bone resorption; Mechanical stimuli.

\section{INTRODUCTION}

Weight-bearing exercise is an essential part of the non-pharmacological management of low bone mass in osteopenia and osteoporosis. ${ }^{9,25,34}$ Weight-bearing exercise produces ground reaction force (GRF), which involves load and has a substantial impact on bone remodeling. ${ }^{13,39}$ Walking is a common and safe weight-bearing exercise that is recommended to improve bone mass in osteopenia. However, the biomechanical characteristics of walking with less axial force on the bone may produce less GRF. 29,30

Bench-step exercise (BE), another type of weight-bearing exercise, offers more benefits than walking exercise (WE) because it has a greater impact on GRF and the strain on the bone. BE exerts an axial force on the bone and therefore produces greater GRF. ${ }^{15,40}$ Zachazewski et al. ${ }^{51}$ analyzed the impact of BE on GRF during the stair ascent (SA) and stair descent (SD) phases 
in the vertical, anteroposterior and lateral directions. The study showed that GRF response increased because the biomechanical aspects of SA and SD differ significantly from the biomechanical aspects of level WE.

During weight-bearing exercise, mechanical loading produces strains that stimulate bone remodeling. Strain induces shear stress on the lacunar and canaliculi fluid flow. Osteocytes, a type of mechanosensory cells, sense the shear stress and begin to activate a remodeling process characterized by increased osteoblast activity and decreased osteoclast activity. 3,4,21,23,26,35

Osteoblast and osteoclast activities can be assessed by examining changes in bone biomarkers. There are several biomarkers commonly used to determine osteoblast and osteoclast activities, such as osteocalcin and bone-specific alkaline phosphatase for osteoblasts and Ctelopeptide (CTX-1) and N-telopeptide (NTX) for osteoclasts. ${ }^{28,43,48,50}$ Increased or decreased osteoblast or osteoclast activity will increase or decrease the levels of these biomarkers.

Previous studies showed the effects of exercise training on changes in plasma osteocalcin and CTX-1. The changes in osteocalcin and CTX-1 levels are related to the osteoblast and osteoclast activity. Bone formation and osteocalcin levels increase following increases in osteoblast activity, whereas bone resorption and CTX-1 levels increase following decreases in osteoclast activity. However, the change in osteocalcin is more consistent than the change in CTX-1. Studies by Tartibian et al. ${ }^{46}$ and Adami et al. ${ }^{1}$ on female subjects showed that osteocalcin increased, whereas CTX-1 remained unchanged or decreased after exercise of moderate intensity. A study by Helge et al. ${ }^{18}$ in some sports found that CTX-1 increased in subjects playing football.

The type of exercise such as BE, as well as WE, is an aerobic exercise recommended to improve cardiorespiratory and muscular fitness. ${ }^{17,32}$
However, BE is much less popular than WE due to insufficient information on how to perform this exercise correctly to make the most of its benefits. Only slightly more information is available about the effects of bench height and stepping rate on GRF. The study by Fujarczuk et al. ${ }^{15}$ might be the only one to have analyzed the relationship of bench-height and stepping rate with GRF. The results showed that stepping rate and bench height determined the GRF impact.

To the best of our knowledge, there has not been a study comparing the effects of WE and $\mathrm{BE}$ on changes in the biomarkers of bone remodeling in osteopenic women. The aim of this study is to compare the effects of $\mathrm{WE}$ and $\mathrm{BE}$ training on osteocalcin and CTX-1 levels in postmenopausal women with osteopenia. We hypothesized that $\mathrm{BE}$ training would increase osteocalcin and decrease CTX-1 more than WE training.

\section{METHODS}

This is a randomized clinical trial with pre-post design. The study was conducted at Posyandu (Integrated Health Center (IHC)), a non-profit health service activity managed by trained volunteers (cadres) and is under supervision by School of Medicine, Atma Jaya Catholic University of Indonesia. Subjects were members visiting Posyandu regularly. Sixty post-menopausal women (aged 50-65 years) were eligible for this study. The inclusion criteria were as follows: sedentary or no history of physical exercise during the last 3 months; having a good balance and mobility; having osteopenia (at least on one site: femur and pelvic) confirmed with dual-energy X-ray absorptiometry (DXA) examination (with $T$-score of $(-1)$ to $(-2))$ and having a body mass index (BMI) of $27 \mathrm{~kg} / \mathrm{m}^{2}$ or lower and were able to complete bench-step test. Bench-step test was conducted as follows: subjects performing step 
up and down the bench at a speed matching the $76 \mathrm{bpm}$ tone of a metronome for $1 \mathrm{~min}$. Subjects were randomly divided into two groups: $\mathrm{BE}$ group $(n=30)$ and WE group $(n=29)$. One subject of WE was lost to follow-up.

The exclusion criteria included the following: having treatment with steroids and hormones; tobacco and alcohol use; taking drugs affecting bone mass such as vitamin D and calcium supplements; evidence of a chronic disease; having muscle injury; having a hypertension (systolic pressure greater than $140 \mathrm{mmHg}$ and diastolic pressure greater than $90 \mathrm{mmHg}$ ); fail to complete 1 min bench-step test and not completing the exercise program. (Flow of recruitment was shown in Fig. 1).

Written informed consent was obtained from each subject by giving signature. This study was approved by the Research Ethics Committee, Faculty of Medicine, University of Indonesia and Cipto Mangunkusumo Hospital. The identity of the participants was confidential and used only for research purposes.

\section{Anthropometric Measurements}

Anthropometric measurements were performed onsite at Posyandu. Body weight was measured using portable digital scales (SECA, Germany) with an accuracy of $0.1 \mathrm{~kg}$, and the subjects were wearing minimal clothing. Height was measured in the Frankfurt standing position without shoes using a wall-mounted stadiometer with an accuracy of $0.1 \mathrm{~cm}$. BMI was calculated by dividing the weight (in kilograms) with the square of height (in meters).

\section{DXA Examination}

DXA scans were used to assess bone mineral density (BMD) in a hospital located in the southern part of Jakarta. BMD was performed using DXA

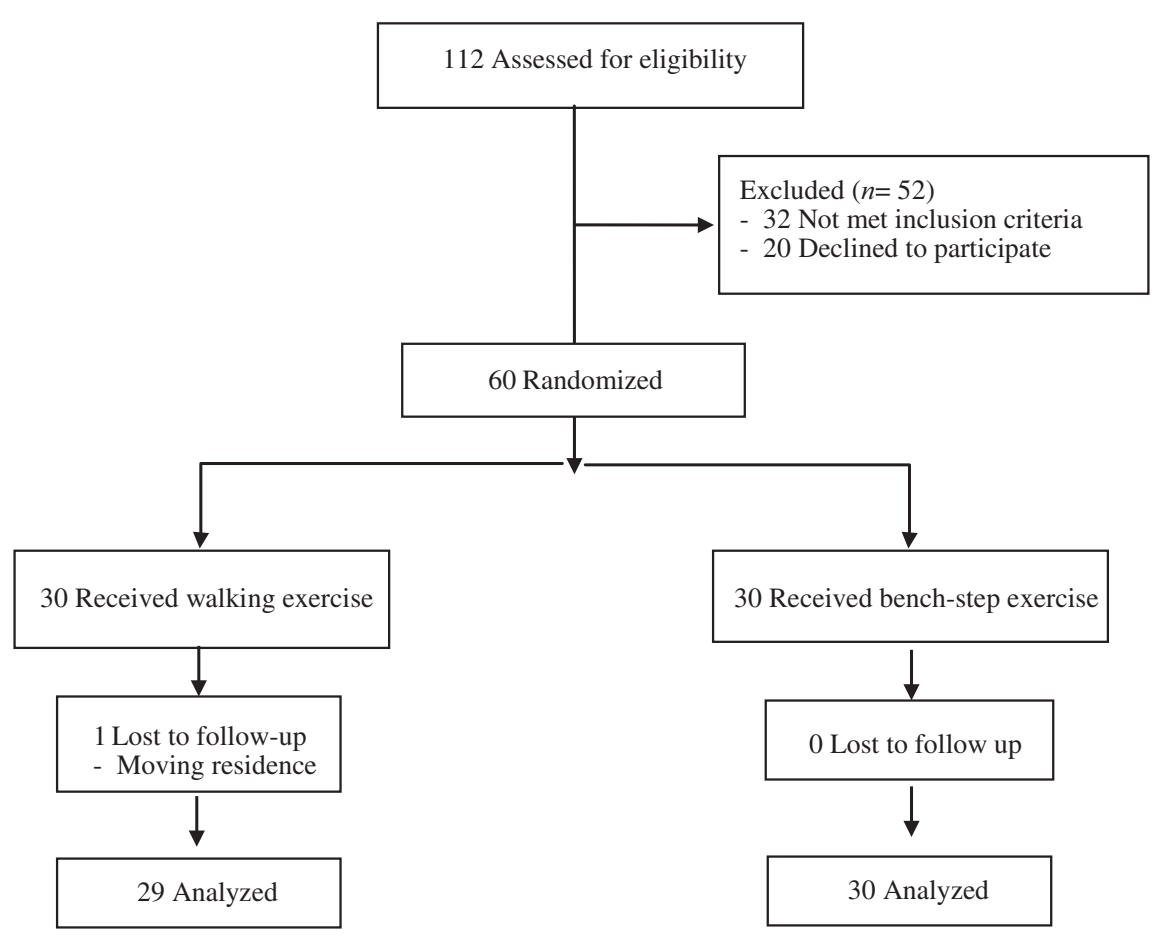

Fig. 1 Flow diagram of subjects recruitment, exercise intervention and follow-up. 
(Lunar Prodigy, GE Healthcare, USA). The DXA machine was calibrated daily according to the manufacturer's instructions. Bone sites for scan were selected as recommended by the International Society for Clinical Densitometry. DXA scans were performed on the spine (L1-L4) and left femur (femoral neck, trochanter, femoral shafts, total hip). ${ }^{8,12}$

\section{Exercise Program}

$B E$

The exercise was performed using a bench made of wood with a height of $20 \mathrm{~cm}$ and a surface of $1 \mathrm{~m}^{2}$. In each session, BE training was performed for $1 \mathrm{~min}$ followed by $30 \mathrm{~s}$ of rest interval, for a total exercise time of $15 \mathrm{~min}$. The $30 \mathrm{~s}$ of interval was intended for bone sensitivity recovery to mechanical stimuli. ${ }^{37,38}$

The subjects were instructed to ascend and descend the bench, starting with the first foot landing on the bench, followed by the second foot; then, the first foot landed on the floor, followed by the second foot. The first foot was changed alternately right or left for every training session to obtain balanced stimuli on both legs. Each step was synchronized with a beat of a metronome set at $76 \mathrm{bpm}$. The speed was in accordance with average physical fitness of the subjects.

\section{WE}

The exercise was performed outdoor for a duration of $15 \mathrm{~min}$ for each session and at a moderate intensity. The average heart rate was maintained in $64-76 \%$ of the heart rate training zone. Heart rate was monitored using a digital heart rate monitor (Polar Heart Rate Monitor).

These exercises were conducted three times a week for 12 weeks. The exercise program was in accordance with the recommendation from American College of Sports Medicine for elderly people with low physical activity and fitness. ${ }^{20,36}$

\section{Samples and Biochemical Analysis}

An aliquot of $10 \mathrm{~mL}$ blood samples was drawn from the median cubital vein using vacutainers filled with $5 \mathrm{~mL}$ EDTA anticoagulant after $12 \mathrm{~h}$ of overnight fasting. Blood samples were taken twice from each subject, before and after 12 weeks of exercise. All blood procedures were done by trained laboratory officers.

Osteocalcin was measured using a human osteocalcin instant enzyme-linked immunosorbent assay (ELISA) produced by eBioscience (California, USA.BMS-2020-INST). The lowest detection limit for sensitivity was $0.2 \mathrm{ng} / \mathrm{mL}$. The calculated overall intra-assay and inter-assay coefficients of variation (CV) were $8.3 \%$ and $8.1 \%$, respectively. The range of normal values for osteocalcin was $2.3-3.6 \mathrm{ng} / \mathrm{mL}^{22}$

CTX-1 was measured using the human (CTX-1 ELISA) kit produced by Cusabio (Wuhan, China. CSB-E11224h). The lowest measurement sensitivity that could be detected was $0.156 \mathrm{ng} /$ $\mathrm{mL}$. The detection range was between $0.625 \mathrm{ng} /$ $\mathrm{mL}$ and $40 \mathrm{ng} / \mathrm{mL}$. The precise intra-assay and inter-assay $\mathrm{CV}$ were $<8 \%$ and $<10 \%$, respectively. The range of normal CTX-1 levels was $0.5-2 \mathrm{ng} / \mathrm{mL}^{14}$

\section{Statistical Analysis}

Values of subject's characteristics, BMD and biomarker were expressed as mean and SD. Normality of the data distribution was tested using a Shapiro-Wilk test. Paired $t$-test or Wilcoxon test was used to compare osteocalcin and CTX-1 levels before and after 12 weeks of exercise in both groups. Mann-Whitney test was used to determine the differences of changes in osteocalcin and CTX-1 levels between the BE and WE groups. The level of significance was defined as $P<0.05$. Statistical analysis was performed using SPSS version 17.0 for Windows (SPSS Inc., Chicago, IL, USA). 


\section{RESULTS}

Fifty-nine subjects were diagnosed with osteopenia, but two patients were diagnosed with osteoporosis during lumbar BMD scanning and one other patient was diagnosed with osteoporosis upon pelvic BMD scanning. Characteristics of the subjects included all factors that may affect the study results. As shown in Table 1, there are no significant differences between the $\mathrm{BE}$ and WE groups for all characteristics included age, age at menopause, duration of menopause, weight, height, BMI and BMD of the several sites (lumbar L1-L4, neck, trochanter, shaft and total femur).
All of the subjects completed the exercise program. Dependent $t$-test or Wilcoxon test showed an increase in the osteocalcin levels of both groups after 36 exercise sessions $(P=0.000$ for $\mathrm{BE}$ and $P=0.010$ for WE). Osteocalcin increased by $13.3 \%$ and $8.8 \%$ after the $\mathrm{BE}$ and $\mathrm{WE}$, respectively. Wilcoxon test showed that CTX-1 increased by $33.3 \%$ and $50 \%$ after the $\mathrm{BE}$ and $\mathrm{WE}$, respectively $(P=0.001$ for $\mathrm{BE}$ and $\mathrm{WE}$; shown in Table 2). When the groups were compared, we found differences in the increased levels of osteocalcin and CTX-1 between the groups. The BE group showed greater increases in osteocalcin than the WE group but not significant

Table 1 Subjects Characteristics of BE and WE Groups.

\begin{tabular}{|c|c|c|c|}
\hline & $\begin{array}{c}\text { WE } \\
(n=29)\end{array}$ & $\begin{array}{c}\text { BE } \\
(n=30)\end{array}$ & $P$ \\
\hline Age (years) & $57.71 \pm 5.31$ & $58.07 \pm 5.39$ & 0.79 \\
\hline Age at menopause (years) & $53.75 \pm 2.69$ & $53.78 \pm 2.82$ & 0.96 \\
\hline Duration of menopause (years) & $3.96 \pm 3.38$ & $4.30 \pm 3.72$ & 0.72 \\
\hline Weight $(\mathrm{kg})$ & $58.24 \pm 9.80$ & $56.68 \pm 9.19$ & 0.52 \\
\hline Height (cm) & $150.73 \pm 5.27$ & $149.24 \pm 3.55$ & 0.20 \\
\hline $\mathrm{BMI}\left(\mathrm{kg} / \mathrm{m}^{2}\right)$ & $25.61 \pm 3.87$ & $25.41 \pm 3.81$ & 0.84 \\
\hline \multicolumn{4}{|l|}{ Bone mineral density } \\
\hline Lumbar (L1-L4) $\left(\mathrm{g} / \mathrm{cm}^{2}\right)$ & $0.905 \pm 0.16$ & $0.920 \pm 0.14$ & 0.71 \\
\hline $\operatorname{Neck}\left(\mathrm{g} / \mathrm{cm}^{2}\right)$ & $0.764 \pm 0.15$ & $0.740 \pm 0.15$ & 0.51 \\
\hline Trochanter $\left(\mathrm{g} / \mathrm{cm}^{2}\right)$ & $0.634 \pm 0.11$ & $0.640 \pm 0.13$ & 0.85 \\
\hline Shaft $\left(\mathrm{g} / \mathrm{cm}^{2}\right)$ & $0.994 \pm 0.17$ & $0.980 \pm 0.19$ & 0.75 \\
\hline Total femur $\left(\mathrm{g} / \mathrm{cm}^{2}\right)$ & $0.816 \pm 0.13$ & $0.815 \pm 0.14$ & 0.98 \\
\hline
\end{tabular}

Notes: BE: bench step exercise; BMI: body mass index; WE: walking exercise.

Table 2 The Changes in Osteocalcin and CTX-1 Levels.

\begin{tabular}{lcccc}
\hline & & Pre-exercise & Post-exercise & $\Delta$ \\
\hline Osteocalcin $(\mathrm{ng} / \mathrm{mL})$ & BE & $3.26 \pm 0.82$ & $3.73 \pm 1.02$ & $0.47 \pm 0.20^{*}$ \\
& WE & $3.42 \pm 0.75$ & $3.92 \pm 0.93$ & $0.50 \pm 0.11^{*}$ \\
CTX-1 (ng/mL) & BE & $1.83 \pm 0.87$ & $2.32 \pm 0.73$ & $0.49 \pm 0.78^{*}$ \\
& WE & $2.16 \pm 0.73$ & $3.26 \pm 1.98$ & $1.10 \pm 1.64^{* \dagger}$ \\
\hline
\end{tabular}

Notes: BE: Bench step exercise; CTX-1: C-telopeptide of type 1 collagen; WE:

Walking exercise.

*Significant different within group $(p<0.05)$.

Significant different between groups $(p<0.05)$. 
Table 3 The Changes in Osteocalcin and CTX-1 Levels Based on BMD Classification.

\begin{tabular}{|c|c|c|c|c|c|c|c|}
\hline & \multicolumn{4}{|c|}{ Osteocalcin (ng/ml) } & \multicolumn{3}{|c|}{ CTX (ng/ml) } \\
\hline & & Pre-exercise & Post-exercise & $\Delta$ & Pre-exercise & Post-exercise & $\Delta$ \\
\hline \multirow[t]{2}{*}{ Lumbal DXA } & Normal $(n=21)$ & $3.19 \pm 0.78$ & $3.64 \pm 0.98$ & $0.46 \pm 0.19^{*}$ & $2.11 \pm 0.91$ & $3.08 \pm 2.12$ & $0.96 \pm 1.92^{*}$ \\
\hline & Low $(n=38)$ & $3.42 \pm 0.78$ & $3.93 \pm 0.97$ & $0.51 \pm 0.19 *$ & $1.92 \pm 0.93$ & $2.62 \pm 1.11$ & $0.70 \pm 0.79 *$ \\
\hline \multirow[t]{2}{*}{ Hip DXA } & Normal $(n=24)$ & $3.28 \pm 0.80$ & $3.75 \pm 1.00$ & $0.48 \pm 0.20^{*}$ & $1.97 \pm 0.89$ & $2.91 \pm 2.02$ & $0.94 \pm 1.80^{*}$ \\
\hline & Low $(n=35)$ & $3.38 \pm 0.78$ & $3.88 \pm 0.97$ & $0.50 \pm 0.19^{*}$ & $2.00 \pm 0.95$ & $2.70 \pm 1.12$ & $0.69 \pm 0.81^{*}$ \\
\hline
\end{tabular}

Notes: CTX-1: C-telopeptide of type 1 collagen ; DXA: Dual-energy X-ray absorptiometry.

*Significant different within group $(p<0.05)$.

$(P>0.367)$, whereas the WE group showed greater increases in CTX-1 $(P<0.048$; Furthermore, the changes of osteocalcin and CTX-1 were analyzed based on the BMD classification. The results are shown in Table 3 ).

The increase of osteocalcin and CTX-1 within a group were significant. In the contrary, the increase of osteocalcin and CTX-1 between groups were not significant.

\section{DISCUSSION}

This study compared the effects of WE and BE on bone remodeling biomarkers. After 12 weeks of exercise, there was a general increase in CTX-1 as well as in osteocalcin. Comparing the results shows no statistically significant difference between the $\mathrm{WE}$ and $\mathrm{BE}$ groups in terms of the increased osteocalcin. In addition, the increased CTX-1 level resulting from WE was significantly higher than that resulting from $\mathrm{BE}$.

The change in osteocalcin is determined per exercise period or per single bout of exercise or training. The change in osteocalcin after a single bout of exercise is unclear; it could decrease, ${ }^{19}$ remain unchanged ${ }^{27}$ or increase. ${ }^{16,42}$ Conversely, the change in osteocalcin after a period of training is more obvious and tends to increase. After 2-3 months of exercise, the subjects enter an adaptation phase. A study by Adami et al. ${ }^{1}$ found that training exercise with moderate intensity for
1 month increased osteocalcin by up to $25 \%$. Tartibian et al. ${ }^{46}$ found increased osteocalcin in post-menopausal women following 24 weeks of exercise with an intensity of $65 \%$ of the maximal heart rate. In this study, osteocalcin increased by $8.8 \%$ and $13.3 \%$ after $\mathrm{WE}$ and $\mathrm{BE}$, respectively. The increased levels of osteocalcin in both groups indicated an effect of training on bone formation. The adaptation process of bone formation occurs when the osteocytes produce mechanical signals and activate bone morphogenetic proteins, WntS, prostaglandin E2 and NO. ${ }^{11,24,33}$ Then, the recruitment, differentiation and activation of osteoblasts are amplified, and bone formation ensues. However, the increased levels of osteocalcin between the groups were not significantly different. This result might be related to the sensitivity of the osteoblasts; osteoblasts have the same degree of sensitivity to any weight-bearing exercise. The GRF produced by axial loading during $\mathrm{BE}$ with moderate intensity in this study was not strong enough to induce greater osteoblast and bone formation.

Comparing the increases in osteocalcin between the two groups, bone formation can potentially be improved further by modifying the exercise program, for instance, by increasing the stepping rate as well as extending the duration of exercise and training. BE may potentially improve bone formation further through modifying the exercise program by increasing the 
stepping rate and the duration of exercise and training. The bench height used in this study was in the same range as the bench height of previous work and was comfortable for the subjects. The stepping rate, duration of exercise and training in this study were adjusted to the subjects' physical ability and fitness and were lower than those in previous studies. ${ }^{15,32,41,44}$ Modifying the training program to strengthen the effect of $\mathrm{BE}$ on mechanical load is still possible but should be performed gradually.

In contrast to the findings for osteocalcin, we found increases in CTX in both groups. This finding was not consistent with our hypothesis. Unlike osteocalcin, the change in CTX-1 after training was unclear. Studies by $\mathrm{Alp}^{2}$ on premenopausal women and by Wen et al. ${ }^{49}$ on postmenopausal women showed that CTX-1 decreased after 2 months of training with moderate intensity in $60-85 \%$ of maximal heart rate, $40 \mathrm{~min}$ per session, five times per week and $75-85 \%$ of heart rate reserve, $90 \mathrm{~min}$ per session, three times per week, respectively. A study by Adami et al. ${ }^{1}$ found that CTX-1 was unchanged after 1 month of training ( $90 \mathrm{~min} / \mathrm{session}, 3-4$ times/week). Tartibian et al. ${ }^{46}$ reported that 3 months of aerobic exercise at light and moderate intensity decreased CTX levels (25-30 min/session, 3-4 times per week, $45-55 \%$ of maximal heart rate). ${ }^{18}$ Compared with previous studies, the duration of each session in this study was much shorter, which may lead to less suppression of osteoclast activity. In addition, bone resorption and osteoclast activity were greater in post-menopausal subjects, and neither type of exercise training was able to balance the pace and halt the bone resorption. This reason may explain why CTX-1 levels remained high.

The increase in CTX-1 in this study indicated that bone resorption was still ongoing. The mechanism of increased CTX-1 after a period of training might be explained as follows: exercise is associated with bone remodeling under certain conditions. During exercise, muscle contraction causes changes in the calcium metabolism. Calcium will trigger muscle contraction, but in the absence of calcium, the interaction of actin and myosin will be prevented. Therefore, the calcium intake requirements will increase during exercise, and parathyroid hormone will be stimulated to manage calcium regulation. 5,6,10,31,45,47

Further analysis was performed to evaluate the changes in osteocalcin and CTX-1 on different BMD classification. The result showed on both normal and low BMD at lumbal and hip, exercise increased osteocalcin and CTX-1. There were similarity between increased osteocalcin and CTX-1 in both normal BMD and low BMD. Based on the increment it shown that the effect of BMD on bone remodelling is not significant during the low-moderate intensity exercise. This is in accordance with a previous study. ${ }^{7}$ Biomarkers and BMD were not changed significantly between control and exercise group in postmenopausal, whereas increased greater significantly in exercise group than in control in premenopausal women. Allegedly due to little heavier, poorer muscle performance, and lower values for BMD, postmenopausal women have dramatically increased biomarkers regardless of BMD and training status. ${ }^{7}$

This study may be the first to compare these two weight-bearing exercises and their respective effects on biomarkers of bone remodeling. As such, our work provides the most up-to-date information on which exercise is more effective in improving bone mass. The BE protocol in this study could be used as a reference to conduct further research or to provide an exercise prescription for osteopenia.

This study has certain limitations. First, the osteocalcin and CTX-1 levels were only measured twice. The first sample was taken prior to the beginning of exercise training, and the second 
was taken $24 \mathrm{~h}$ after the last session. We suggest taking at least two more samples to obtain patterns of acute and training responses: one post-exercise sample after the first session and one prior to the last exercise session. Second, only one biomarker each for osteoblasts and osteoclasts was analyzed. The effects of the exercises on bone formation and resorption would be clearer and more certain if the evaluation had involved more than one biomarker each for osteoblasts and osteoclasts.

\section{CONCLUSION}

Both BE and WE increase osteocalcin and CTX-1 in post-menopausal women with osteopenia. The increase in osteocalcin in all subjects confirmed that both WE and BE exercises resulted the same effects on bone formation. The lower degree of increase in CTX-1 resulting from BE indicated that bone resorption appears to have been inhibited more effectively by $\mathrm{BE}$ than by WE. Our finding suggests that BE with a few modifications to the stepping rate and duration of exercise may provide more benefits and can be considered as an exercise program to help improve bone mass.

Duration of exercise in this study might be too short to generate different changes of the biomarkers between groups. We recommend a future study with longer duration of exercise to obtain the different effect of exercise types and significant changes of the biomarkers.

\section{ACKNOWLEDGMENTS}

I would like to express my gratitude to Atma Jaya Catholic University and Directorate General of Higher Education (DGHE), Ministry of Research, Technology and Higher Education (Simlitabmas) for funding. I also thank Dr Alida Harahap, Dr Sugianto Ali and Dr Jul Kurniarobbi for giving valuable advices in this research. I would also like to extend my thanks to my friends Dr Nawanto Agung, Dr Wahyuni R. Homan and everyone else in Physiology Department of Atma Jaya for their kind support and assistance during research and writing of this article.

We represent that this submission is original work, and is not under consideration for publication with any other journal.

\section{References}

1. Adami S, Gatti D, Viapiana O, Fiore CE, Nuti R, Luisetto G, Ponte M, Rossini M; BONTURNO Study Group. Physical activity and bone turnover markers: A cross-sectional and a longitudinal study. Calcif Tissue Int 83: 388-392, 2008.

2. Alp A. Effects of aerobic exercise on bone specific alkaline phosphatase and urinary CTX levels in premenopausal women. Türk J Phys Med 59: 310-313, 2013.

3. Bakker AD, Klein-Nulend J. Mechanisms of osteocyte mechanotransduction. Clin Rev Bone Miner Metab 4(8): 163-169, 2010.

4. Bakker AD, Klein-Nulend J. Role of osteocytes in the adaptation of bone to mechanical loading. Fut Rheumatol 3: 571-586, 2008.

5. Barry DW, Hansen KC, Van Pelt RE, Witten M, Wolfe P, Kohrt WM. Acute calcium ingestion attenuates exerciseinduced disruption of calcium homeostasis. Med Sci Sports Exerc 43(4): 617-623, 2011.

6. Barry DW, Kohrt WM. Acute effects of 2 hours of moderate-intensity cycling on serum parathyroid hormone and calcium. Calcif Tissue Int 80(6): 359-365, 2007.

7. Bassey EJ, Rothwell MC, Littlewood JJ, Pye DW. Preand postmenopausal women have different bone mineral density responses to the same high-impact exercise. J Bone Miner Res 13(12): 1805-1813, 1998.

8. Blake GM, Fogelman I. The role of DEXA bone density scans in the diagnosis and treatment of osteoporosis. Postgrad Med J 83(982): 509-517, 2007.

9. Body JJ, Bergmann P, Boonen S, Boutsen Y, Bruyere O, Devogelaer JP, Goemaere S, Hollevoet N, Kaufman JM, Milisen K, Rozenberg S, Reginster JY. Non-pharmacological management of osteoporosis: A consensus of the Belgian Bone Club. Osteoporos Int 22(11): 2769-2788, 2011.

10. Bouassida A, Latiri I, Bouassida S, Zalleg D, Zaouali M, Feki Y, Gharbi Y, Zbidi A, Tabka Z. Parathyroid 
hormone and physical exercise: A brief review. J Sports Sci Med 5(3): 367-374, 2006.

11. Burger EH, Klein-Nulend J. Mechanotransduction in bone-role of the lacuno-canalicular network. FASEB J 13(Suppl): 101-112, 1999.

12. Celi M, Rao C, Scialdoni A, Tempesta V, Gasbarra E, Pistillo P, Tarantino U. Bone mineral density evaluation in osteoporosis: Why yes and why not? Aging Clin Exp Res 25(Suppl 1): S47-S49, 2013.

13. Chan CW, Rudins A. Foot biomechanics during walking and running. Mayo Clin Proc 5(69): 448-461, 1994.

14. Csb-eh CN. Human cross-linked carboxy-terminal telopeptide of type I collagen (CTX-I) ELISA Kit. 1-17. Available at: http://www.cusabio.com/ELISA-Kit/ Human-Cross-linked-Carboxy-terminal-telopeptide-oftype-\%E2\%85\%A0-collagen-CTX-I-ELISA 62292.html.

15. Fujarczuk K, Winiarski S, Rutkowska-Kucharska A. Ground reaction forces in step aerobics. Acta Bioeng Biomech 8(2): 111-118, 2006.

16. Guillemant J, Accarie C, Peres G, Guillemant S. Acute effects of an oral calcium load on markers of bone metabolism during endurance cycling exercise in male athletes. Calcif Tissue Int 74(5): 407-411, 2004.

17. Hallage T, Krause MP, Haile L, Miculis CP, Nagle EF, Reis RS, Da Silva SG. The effects of 12 weeks of step aerobics training on functional fitness of elderly women. J Strength Cond Res 24(8): 2261-2266, 2010.

18. Helge EW, Andersen TR, Schmidt JF, Jørgensen NR, Hornstrup T, Krustrup P, Bangsbo J. Recreational football improves bone mineral density and bone turnover marker profile in elderly men. Scand J Med Sci Sports 24(Suppl. 1): 98-104, 2014.

19. Herrmann M, Müller M, Scharhag J, Sand-Hill M, Kindermann W, Herrmann W. The effect of endurance exercise-induced lactacidosis on biochemical markers of bone turnover. Clin Chem Lab Med 45: 1381-1389, 2007.

20. Heyward VH. Advances Fitness Assessment and Exercise Prescription. 3rd ed., Human Kinetics Company, Champaign, 1991.

21. Huang C, Ogawa R. Mechanotransduction in bone repair and regeneration. FASEB J 24(10): 3625-3632, 2010.

22. Human Osteocalcin Instant ELISA ${ }^{\mathrm{TM}}$ Kit. Product Information \& Manual. Enzyme-linked immunosorbent assay for quantitative detection of human osteocalcin. BMS2020INST. Available at: http://tools.thermofisher. com/content/sfs/manuals/2020INST.pdf. [Accessed on 11 July 2017].

23. Klein-Nulend J, Bakker AD, Bacabac RG, Vatsa A, Weinbaum S. Mechanosensation and transduction in osteocytes. Bone 54(2): 182-190, 2013.

24. Klein-Nulend J, Bacabac RG, Bakker AD. Mechanical loading and how it affects bone cells: The role of the osteocyte cytoskeleton in maintaining our skeleton. Eur Cell Mater 24(2): 279-291, 2012.

25. Levine JP. Pharmacologic and non-pharmacologic management of osteoporosis. Clin Cornerstone 8(1): 40-53, 2006.

26. Martin TJ, Sims NA. How cells communicate in the bone remodeling process. J Korean Endocr Soc 25(1): 1-8, 2010.

27. Maïmoun L, Simar D, Malatesta D, Caillaud C, Perruchon E, Couret I, Rossi M, Mariano-Goulart M. Response of bone metabolism related hormones to a single session of strenuous exercise in active elderly subjects. Br J Sports Med 39(8): 497-502, 2005.

28. McCormick RK. Osteoporosis: Integrating biomarkers and other diagnostic correlates into the management of bone fragility. Altern Med Rev 12(2): 113-145, 2007.

29. Milgrom C, Finestone A, Levi Y, Simkin A, Ekenman I, Mendelson S, Millgram M, Nyska M, Benjuya N, Burr D. Do high impact exercises produce higher tibial strains than running? Br J Sports Med 34: 195-199, 2000.

30. Milgrom C, Finestone A, Simkin A, Ekenman I, Mendelson S, Millgram M, Nyska M, Larsson E, Burr D. In-vivo strain measurements to evaluate the strengthening potential of exercises on the tibial bone. $J$ Bone Joint Surg Br 82(4): 591-594, 2000.

31. Moreira LD, Fronza FC, Dos Santos RN, Zach PL, Kunii IS, Hayashi LF, Teixeira LR, Kruel LF, Castro ML. The benefits of a high-intensity aquatic exercise program (HydrOS) for bone metabolism and bone mass of postmenopausal women. J Bone Miner Metab 32(4): 411419, 2014.

32. Mori $\mathrm{Y}$, Ayabe M, Yahiro T, Tobina T, Kiyonaga A, Shindo M, Yamada T, Tanaka H. The effects of homebased bench-step exercise on aerobic capacity, lower extremity power and static balance in older adults. Int $J$ Sport Health Sci 4: 570-576, 2006.

33. Mullender M, El Haj AJ, Yang Y, van Duin MA, Burger $\mathrm{EH}$, Klein-Nulend J. Mechanotransduction of bone cells in vitro: Mechanobiology of bone tissue. Med Biol Eng Comput 42: 14-21, 2004.

34. Ossowski ZM, Skrobot W, Aschenbrenner P, Cesnaitiene VJ, Smaruj M. Effects of short-term Nordic walking training on sarcopenia-related parameters in women with low bone mass: A preliminary study. Clin Interv Aging 30(11): 1763-1771, 2016.

35. Protopapadaki A, Drechsler WI, Cramp MC, Coutts FJ, Scott OM. Hip, knee, ankle kinematics and kinetics during stair ascent and descent in healthy young individuals. Clin Biomech (Bristol, Avon) 22: 203-210, 2007.

36. Riebe D. Exercise prescription. ACSM's Guidelines for Exercise Testing and Prescription, Pescatello LS, Arena R, Riebe D, Thompson PD (eds.), 9th edn., Baltimore, 
Lippincott-Williams and Wilkins Company, pp. 204210, 2014.

37. Robling AG, Burr DB, Turner $\mathrm{CH}$. Recovery periods restore mechanosensitivity to dynamically loaded bone. J Exp Biol 204: 3389-3399, 2001.

38. Robling AG, Burr DB, Turner CH. Partitioning a daily mechanical stimulus into discrete loading bouts improves the osteogenic response to loading. J Bone Miner Res 8(15): 1596-1602, 2000.

39. Rodgers MM. Dynamic biomechanics of the normal foot and ankle during walking and running. Phys Ther 68(12): 1822-1830, 1988.

40. Santos-Rocha R, Veloso A, Machado ML. Analysis of ground reaction forces in step exercise depending on step pattern and stepping rate. J Strength Cond Res 23(1): 209-224, 2009.

41. Santos-Rocha RA, Oliveira CS, Veloso AP. Osteogenic index of step exercise depending on choreographic movements, session duration, and stepping rate. $\mathrm{Br} \mathrm{J}$ Sports Med 40(10): 860-866, 2006.

42. Scott JP, Sale C, Greaves JP, Casey A, Dutton J, Fraser WD. The role of exercise intensity in the bone metabolic response to an acute bout of weight-bearing exercise. J Appl Physiol 110(2): 423-432, 2011.

43. Seibel MJ. Biochemical markers of bone turnover: Part I: Biochemistry and variability. Clin Biochem Rev 26(4): 97122, 2005.
44. Skelly WA, Darby LA, Phillips K. Physiological and biomechanical responses to three different landing surfaces during step aerobics. JEP Online 2(6): 70-80, 2003.

45. Szent-Györgyi AG. Calcium regulation of muscle contraction. Biophys J 15(7): 707-723, 1975.

46. Tartibian B, Maleki BH, Kanaley J, Sadeghi K. Longterm aerobic exercise and omega-3 supplementation modulate osteoporosis through inflammatory mechanisms in post-menopausal women: A randomized, repeated measures study. Nutr Metab (Lond) 8: 71-83, 2011.

47. Wakabayashi T. Mechanism of the calcium-regulation of muscle contraction - In pursuit of its structural basis. Proc Jpn Acad Ser B Phys Biol Sci 91(7): 321-350, 2015.

48. Watts NB. Clinical utility of biochemical markers of bone remodeling. Clin Chem 45(8): 1359-1368, 1999.

49. Wen HJ, Huang TH, Li TL, Chong PN, Ang BS. Effects of short-term step aerobics exercise on bone metabolism and functional fitness in postmenopausal women with low bone mass. Osteoporos Int 27(8): 1246-1261, 2016.

50. Wheater G, Elshahaly M, Tuck SP, Datta HK, Van Laar JM. The clinical utility of bone marker measurements in osteoporosis. J Transl Med 11: 201-214, 2013.

51. Zachazewski JE, Riley PO, Krebs DE. Biomechanical analysis of body mass transfer during stair ascent and descent of healthy subjects. J Rehabil Res Dev 30(4): 412422, 1993. 